\title{
Report from the PHLS Communicable Disease Surveillance Centre
}

During March meningococcal meningitis was again in the news; there was an outbreak of salmonellosis in a hospital in the north west; a cluster of cases of legionnaires' disease associated with Torremolinos, Spain, was reported; a case of human rabies occurred in Birmingham in a child who had been bitten by a dog in India; and the number of cases of AIDS rose to a cumulative total of 734 .

\section{Meningococcal meningitis}

There were 414 provisional notifications of meningococcal meningitis in the first quarter of 1987, compared with 245 in 1986 and 161 in 1985, and this figure was similar to that in the first quarter of 1974 (412), the peak of the previous epidemic. In most years about one third of notifications occur in the first quarter; if the same pattern holds in 1987 the total for the year will probably be about the same as that in 1974 .

In 1985-6 the increase was associated with localised outbreaks due to Neisseria meningitidis group B type 15 , the most notable of which took place in Gloucestershire. More recently, however, there has been a rise in infections due to group $\mathrm{C}$ strains, and two small outbreaks were reported, one in a school and the other in a military training establishment. In both these outbreaks vaccination was offered with a group $\mathrm{A}$ and $\mathrm{C}$ vaccine, after which no further cases were reported.

With the rising incidence of this potentially fatal infection, general practitioners need to be alerted to ensure early diagnosis and prompt treatment. When the diagnosis is suspected intramuscular penicillin should be given immediately rather than be delayed until the patients' arrival in hospital, especially if the journey is likely to be long.

\section{Hospital salmonellosis}

In February and March there was an outbreak of salmonellosis in a psychiatric and psychogeriatric hospital of nearly 400 beds near Blackpool. Thirty two patients and two staff became ill, and 66 patients and 15 staff were shown to be infected with Salmonella enteritidis phage type 8 . The first patient became ill on 21 February and the last on $8 \mathrm{March}$, and in between these dates there was one death in which salmonellosis was a contributory factor. Three small outbreaks had been identified at the hospital in the previous 18 months, all of which were shown by the PHLS division of enteric pathogens to be due to the same organism and all of which appeared to be caused predominantly by spread from person to person with no evidence of a food source. In the most recent outbreak, however, infections occurred on nine separate wards within the first five days, which suggested a common source; but despite intensive and meticulous investigation none was identified.

In the wake of the large outbreak of foodborne salmonellosis at the Stanley Royd Hospital in Wakefield in 1984 there has been an increased awareness of diarrhoeal illness in hospitals, and indeed more intensive surveillance may have brought to light the four episodes in the Blackpool hospital, which might otherwise have escaped notice. It is surprising, therefore, that overall the number of hospital outbreaks of salmonellosis reported has not increased but, on the contrary, has declined. In the late 1960s and early 1970s there were about 50 outbreaks reported a year but by the 1980s this had declined to fewer than half this number; since 1984 the number has not exceeded 20 a year (figure).

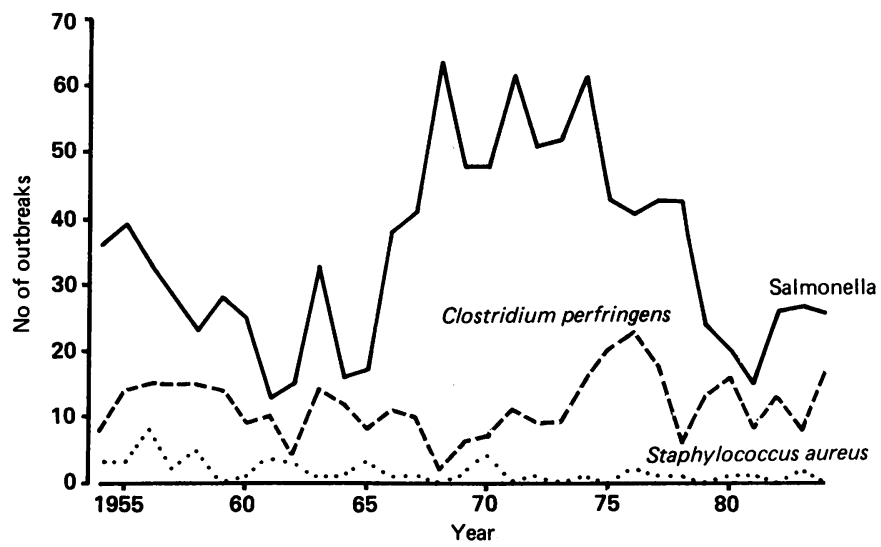

Incidence of salmonellosis and food poisoning in hospitals in England and Wales 1954-84.

Most hospital outbreaks of salmonellosis are small episodes due to person to person infection after the admission of a patient with mild infection or a symptomless excretor. The incidence of salmonellosis in the general population has continued to rise so that such admissions are likely to have increased, suggesting that the decline in hospital acquired infection is due to increasingly effective infection control measures in hospitals.

Outbreaks of Clostridium perfringens and Staphylococcus aureus food poisoning result from poor food hygiene and personal hygiene and are therefore a better reflection of standards of hygiene in hospital kitchens than are outbreaks of salmonellosis. Here also, despite the increase in reporting of diarrhoeal illness, there has been no rise in the number of reported outbreaks; indeed, there has been little change in the past 30 years, with 10 to 20 outbreaks each year (figure). Perhaps the recent removal of crown immunity and the consequent greater involvement of environmental health officers in the National Health Service may lead to a decline in the next few years.

\section{Legionnaires' disease}

Between December 1986 and March 1987 four confirmed cases of legionnaires' disease were reported among British tourists visiting Torremolinos, Spain; three of them died. Two other cases had been reported in the summer of 1986 from the same resort. The six patients had stayed at three different hotels, and no association with a single possible source has yet been identified. The Spanish health authorities are performing further investigations and have advised hoteliers in the town on methods of preventing the infection. 
About 200 cases of legionnaires' disease were reported by medical microbiologists to the Communicable Disease Surveillance Centre (CDSC) each year in England and Wales after 1979, when the surveillance scheme based on laboratory reports became established; in over one third of cases the infection was probably acquired abroad. One aim of the scheme is to detect clusters of cases associated with places or premises so that detailed investigation can be made and control measures quickly applied. Several such clusters associated with hotels, hospitals, and other buildings have been identified in the past 10 years, some of them with hotels overseas. Perhaps the most notable overseas outbreak was the "Benidorm epidemic" of 1980 associated with contamination of the domestic water supply to a local hotel, in which cases were identified in retrospect extending over the previous seven years. Control measures, which included raising the hot water temperature to $50^{\circ} \mathrm{C}$ and maintaining a chlorine level of one to two parts per million at the taps, stopped the outbreak. Continued surveillance since the outbreak has not detected any cases associated with the hotel for over seven years, showing the efficacy of these measures.

Clinicians will wish to seek microbiological investigation of cases of atypical pneumonia, particularly during the summer months, when the incidence of legionnaires' disease is likely to increase. Medical microbiologists are invited to report confirmed or suspected cases promptly to the Communicable Disease Surveillance Centre (61 Colindale Avenue, London NW9 5EQ; 01200 6868) in England and Wales and the Communicable Diseases (Scotland) Unit (Ruchill Hospital, Glasgow G20 9NB; 0419467120 ) in Scotland so that early inquiries about possible common sources of infection can be made.

\section{Rabies}

An 8 year old boy was admitted to hospital in Birmingham with rabies on 15 March and died two weeks later. He had been bitten on the ankle by a dog on 13 January while visiting relatives in India but unfortunately did not receive postexposure prophylaxis. This is the nineteenth imported case of human rabies since the disease was eradicated from the dog population of Britain in 1902, all but two of which have occurred since the end of the second world war. Thirteen of the victims acquired the infection after dog bites in the Indian subcontinent, three in Africa, two in Europe (both before 1946), and one in Asia.

Travellers do not always appreciate that rabies is endemic in dogs, particularly semidomesticated dogs, in Asia and Africa and that these animals present a much greater hazard than in Europe, where normally rabies is confined to wildlife, mainly foxes. Travellers should be advised not to handle animals and if they are inadvertently bitten, scratched, or licked by a possibly infected animal they should seek immediate medical advice.

\section{Acquired immune deficiency syndrome}

By the end of the first quarter of 1987, 734 cases of AIDS and 405 deaths had been reported to CDSC and $C D(S) U$; these figures show a continuing upward trend, the numbers doubling about every 10 months. The geographical distribution remained unaltered, with $566(77 \%)$ cases reported from the four Thames regions, most of them from North West Thames, although increasing numbers of cases are being reported in most regions. Most of the cases (87\%) were in homosexual or bisexual men (table) and a greater proportion of cases in this "risk group" were reported from the Thames regions than elsewhere.

Clinicians will be aware of the importance of monitoring the spread of the AIDS epidemic in Britain and of the essential contribution that their confidential reports have made to the surveillance scheme. Now that the disease has appeared in most parts of Britain and is likely to spread outside the initially recognised "risk groups" all clinicians are invited to report cases or suspected cases in confidence to the Communicable Disease Surveillance Centre or to the Communicable Diseases (Scotland) Unit. A clinical
Acquired immune deficiency syndrome in Britain. Cases reported to 31 March 1987

\begin{tabular}{|c|c|c|c|c|}
\hline \multirow[b]{2}{*}{ Patient characteristic } & \multicolumn{3}{|c|}{ No of cases } & \multirow{2}{*}{$\begin{array}{c}\text { No } \\
\text { of } \\
\text { deaths }\end{array}$} \\
\hline & Male & Female & Total & \\
\hline Homosexual/bisexual men & 640 & - & 640 & 342 \\
\hline Intravenous drug abuser & 8 & 2 & 10 & 5 \\
\hline Homosexual and intravenous drug abuser & 7 & - & 7 & 4 \\
\hline Haemophiliac & 31 & 0 & 31 & 23 \\
\hline \multicolumn{5}{|l|}{ Recipient of blood: } \\
\hline Abroad & 4 & 4 & 8 & 6 \\
\hline Britain & 3 & 2 & 5 & 5 \\
\hline \multicolumn{5}{|l|}{ Heterosexual contact: } \\
\hline Abroad & 13 & 7 & 20 & 11 \\
\hline Britain & 1 & 4 & 5 & 4 \\
\hline Child of HIV positive parent & 3 & 4 & 7 & 4 \\
\hline Other & 0 & 1 & 1 & 1 \\
\hline Total & 710 & 24 & 734 & 405 \\
\hline
\end{tabular}

report form will be provided by these centres or may be available locally from physicians in genitourinary medicine or the department of community medicine.

\section{MATERIA NON MEDICA}

\section{Winning ways}

Each year, as Derby Day approaches and as sons of Blushing Groom take their place in the field, my thoughts return to a late May morning in 1977 when I was a locum orthopaedic registrar taking an outpatient clinic. I was approached by the staff nurse: "Mr Smyth, I wanted to warn you about the next patient. He's a very difficult man; we've had trouble with him on several occasions. Thought I'd let you know."

"Thanks," I replied, without enthusiasm, but then reflected: "Forewarned is forearmed-be thankful."

A few moments later, and quite independently, the physiotherapist addressed me similarly: "The next man is a pretty difficult customer ... often causes trouble in the department. He's already had a row with the ambulancemen this morning. Just wanted to let you know in advance."

"Oh thanks!" I answered, this time a little more gratefully. I was becoming interested, and a little apprehensive.

The man came in and sat down. I nodded a greeting as I completed the previous patient's notes. Then I noticed that the Daily Mirror on his lap lay open at the racing page.

"Oh," I remarked. "Are you interested in horse racing?"

"Have the occasional bet," came the disgruntled, fairly surly reply.

"What do you fancy for the Derby?"

"Dunno. The French horse I s'pose."

The French horse was Blushing Groom. He was the favourite.

"I was in Paris last October," I replied. "I saw him winning the big two year old race, the Grand Criterium."

Instantly the patient was transformed. He leaned forward and questioned me eagerly.

"Were you, doctor? Tell me all about him."

"Well, he's a great horse, a brilliant miler. But I don't know if he'll stay a mile and a half. His sire, you know, was Red God, and he was at his best over six furlongs."

"Yes, but he is a very good horse, isn't he?" ventured the patient.

"Oh yes, undoubtedly." I agreed. Then, "How about this knee of yours?"

"It's much better, doctor. Hasn't been so good for a long time."

I'm afraid that my examination was somewhat perfunctory. Just a rolling up of trouser job, inspection, palpation, and a few passive movements.

"It seems pretty good to me" I said.

"It is, doctor."

"Well, let's not bother you with any more appointments just now. If it does start playing up again, contact our secretary; we'll see you as necessary."

"That's fine, doctor." Then, as he stood up to go, "May I say what a great pleasure it has been to meet you?"

I thanked him and returned the compliment. Sometimes a misspent youth pays dividends.

Blushing Groom ran third. He didn't get the trip. I hope my friend did not have too much on him.- JULIAN SMYTH, London. 